\title{
ASSESSMENT OF HEAT TRANSFER IN FUEL CHANNEL OF INDIAN PHWR UNDER POSTULATED LARGE BREAK LOSS OF COOLANT ACCIDENT: EXPERIMENTAL AND NUMERICAL STUDY
}

\author{
Ketan Ajay $^{*}$, Ravi Kumar', Akhilesh Gupta ${ }^{1}$ \\ ${ }^{1}$ Department of Mechanical and Industrial Engineering, Indian Institute of Technology \\ Roorkee, Roorkee-247667, India
}

kajay@me.iitr.ac.in, ravikfme@iitr.ac.in, akhilfme@iitr.ac.in

\begin{abstract}
The behaviour of the channel under postulated large break LOCA scenario had been a prime safety concern. The radiative heat transfer is predominant in a channel when the convective cooling environment is marred. The estimation of temperature distribution in the fuel pins at elevated temperature is essential from the point of view of hydrogen gas generation and release of fission products. In this paper, the thermal characteristics of a channel for Indian PHWR under critical break failure is studied using experimental and numerical techniques. The experiment is carried out on an Indian PHWR having a fuel bundle of 37-fuel elements. The temperature profiles for different parts of the simulated channel comprising of fuel pins, PT and $\mathrm{CT}$ are obtained under steady condition. The numerical analysis is also performed using ANSYS Fluent 19.0. From the study, it is found that there is a significant radial temperature gradient in the fuel bundle from the center ring to the outer ring. Also, no significant circumferential temperature gradient is observed in the fuel bundle, PT and CT.
\end{abstract}

KEYWORDS: Bundle radiation heat transfer, PHWR, LOCA

\section{INTRODUCTION}

In an Indian PHWR of large capacity (700 MWe), there are 392 horizontal fuel channels, each $6 \mathrm{~m}$ long. The fuel channels are submerged in a large volume of subcooled heavy water moderator contained in a calandria vessel [1]. The temperature of the moderator is maintained at around $65{ }^{\circ} \mathrm{C}$. Each fuel channel consists of twelve short fuel bundles, which are placed inside a Pressure tube (PT). The PT is further housed concentrically inside the Calandria tube (CT). The PT and CT are made of Zirconium 2.5\% Niobium and Zircaloy-2, respectively. The fuel bundle has a configuration of 37 fuel pins, which are arranged in a circular array of 1, 6, 12 and 18 fuel pins in the first, second, third and fourth ring, respectively [1]. Each fuel pin contains pellets of natural uranium dioxide fuel inside the clad tube made of Zircaloy-4. The annular space between the PT and CT is filled with carbon dioxide gas that thermally insulates the fuel channel from the lower-temperature CT. The heavy water as a coolant is fed inside the coolant channel through a closed-loop named primary heat transport system (PHTS) at around $10 \mathrm{MPa}$ pressure and $300^{\circ} \mathrm{C}$ temperature [2]. The coolant draws thermal energy generated through the nuclear fission reaction and exchanges it with the secondary coolant (light water) for the production of useful electrical power. The postulated accidental scenario like loss of coolant accident (LOCA) coincident with the rupture of the emergency core cooling system (ECCS) results in high fuel temperatures. It is because, under such conditions, the convective cooling environment of the reactor channel is marred as superheated steam is the only coolant available for the removal of decay heat of the fuel. In this worst accidental situation, the radiative heat transfer is the 
dominant mode of heat transfer to dissipate the decay heat of the fuel [3-5]. The PT also experiences significant heat-up as it receives heat flux equivalent to that of decay heat from the fuel, which results in its plastic deformation like ballooning deformation, sagging deformation, or both [3]. Several computer codes like CHAN-II [6] and CATHENA [7] are developed to assess the radiative heat flux under postulated critical break LOCA scenario for CANDU reactor. These codes reasonably estimate the temperature of the different components of the coolant channel like fuel pins, PT and CT. However, these two codes have certain limitations as they use a simplified one-dimensional radiation model. Kim et al. [8] performed a numerical study using a CFX code on CANDU reactor with a 28-fuel pin under fully voided conditions. The temperature profile of the cosine shape was obtained along the circumference of the PT. Various experimental studies on the Indian PHWR reactor of 220 MWe capacity has been done in the past to analyze the thermal-mechanical behavior of the channel under the LOCA situation [9-10]. Nitheanandan [11] carried out a numerical study to estimate the radiation heat transfer from the fuel bundle to PT, from PT to CT and from CT to moderator for CANDU 6 reactor. Recently, Ajay et al. [5] performed an experiment on an Indian PHWR under an impaired cooling condition to estimate the radiation heat transfer in the channel having a bundle of 37-fuel elements. In this present study, the thermal behavior of the coolant channel under LBLOCA (large break loss of coolant accident) condition for large capacity Indian PHWR is investigated through experimental and numerical techniques. The steady-state circumferential temperature distribution in each fuel pin of the fuel bundle, PT and CT due to radiative heat transfer is obtained.

\section{EXPERIMENTAL METHODOLOGY}

The schematic of an experimental facility to study the temperature distribution in a coolant channel of 700 MWe IPHWR under the inert environment is shown in the Figure 1. The test-section comprised a 37-fuel pin bundle simulator, PT, CT and moderator tank. The specifications of the test-section are listed in the Table 1. A cross-section view of the test section is shown in the Figure 2. The 37-pin fuel bundle simulator is placed concentrically inside the PT. The PT is then placed concentrically inside the CT in such a way that it extends $75 \mathrm{~mm}$ from both sides of the CT. The CT is fixed on the tank wall with the help of leak-proof gaskets and flanges. The tank is filled with the moderator so that CT is submerged in it. The temperature of the moderator is initially maintained at $65^{\circ} \mathrm{C}$ using immersion heater rods. The annulus space between PT and CT is filled with argon gas, which is done using two end boxes attached towards each side of the tank. The argon gas is introduced in these end boxes. The annular gap between the PT-CT is adjusted through the lead screws. These lead screws are fixed at the bottom, right and left side of the PT towards the exit and inlet section. The screws are used to hold the PT in the desired position firmly. LVDTs are used to monitor this gas-filled gap. The argon is also made to flow inside the PT at a flow rate of $3 \mathrm{~g} / \mathrm{s}$. It is done to create an inert environment in the test-section. The argon gas is initially preheated to a temperature of $150-160{ }^{\circ} \mathrm{C}$ using a preheater.

The 37-pin fuel bundle simulator of an Indian PHWR has an arrangement of four rings. The fuel pins are arranged in such a way that one, six, twelve and eighteen fuel pins are in the first ring, second ring, third ring and fourth ring, respectively. The fabricated fuel bundle simulator is shown in the Figure 3. Each fuel pin has a Kanthal A-1 heater rod that is placed inside the highly pure alumina sleeve, which is done to insulate the fuel pins from the heater electrically. The heater and alumina sleeve assembly is then fixed inside the Zircaloy- 4 clad tube. The two spacers are used to support the fuel pins. Each of the heater rods is connected in a parallel configuration for resistive heating. 


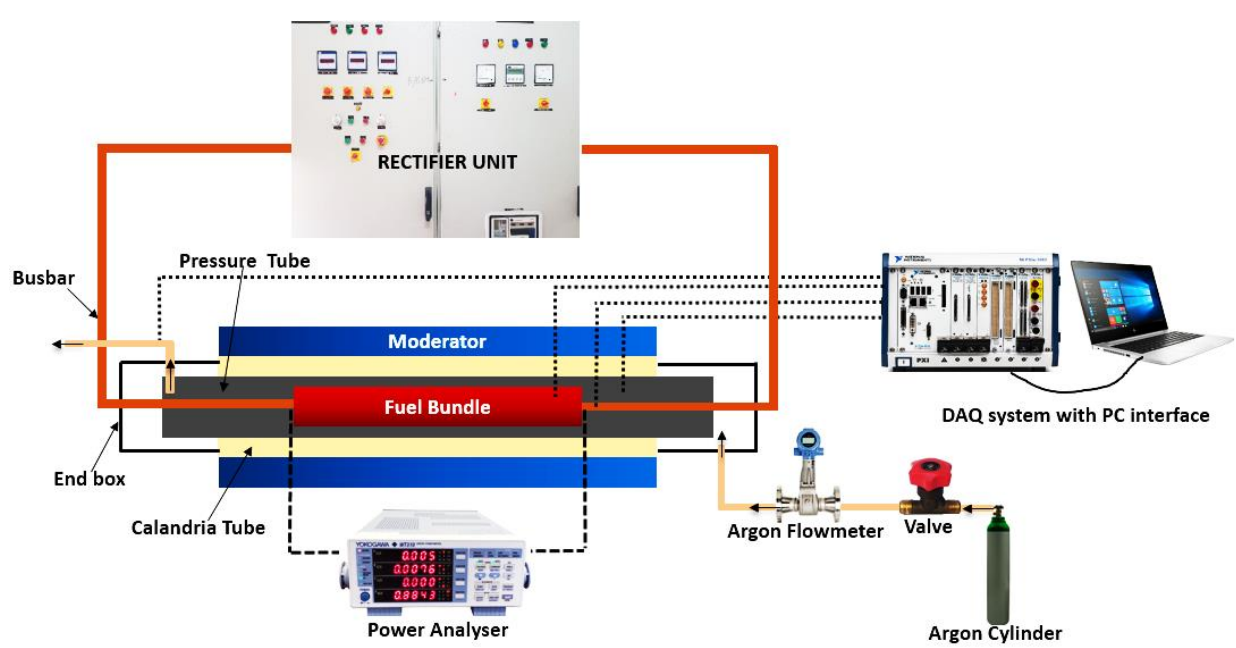

Figure 1: Schematic of the experimental facility

Table 1: Specifications of the test-section

\begin{tabular}{|c|c|c|}
\hline Component & Material & Dimension \\
\hline Fuel Pin & Zircaloy-4 & ID $=11.20 \mathrm{~mm} ; \mathrm{OD}=13.04 \mathrm{~mm} ; \mathrm{L}=1000 \mathrm{~mm}$ \\
\hline Pressure Tube & $\begin{array}{c}\text { Zirconium } 2.5 \% \\
\text { Niobium }\end{array}$ & $\mathrm{ID}=103.80 \mathrm{~mm} ; \mathrm{OD}=112.40 \mathrm{~mm} ; \mathrm{L}=1600 \mathrm{~mm}$ \\
\hline Calandria Tube & Zircaloy-2 & ID $=128.30 \mathrm{~mm} ; \mathrm{OD}=132.10 \mathrm{~mm} ; \mathrm{L}=1450 \mathrm{~mm}$ \\
\hline Tank & Stainless steel & $\mathrm{L}=1400 \mathrm{~mm} ; \mathrm{W}=500 \mathrm{~mm} ; \mathrm{H}=750 \mathrm{~mm}$ \\
\hline
\end{tabular}

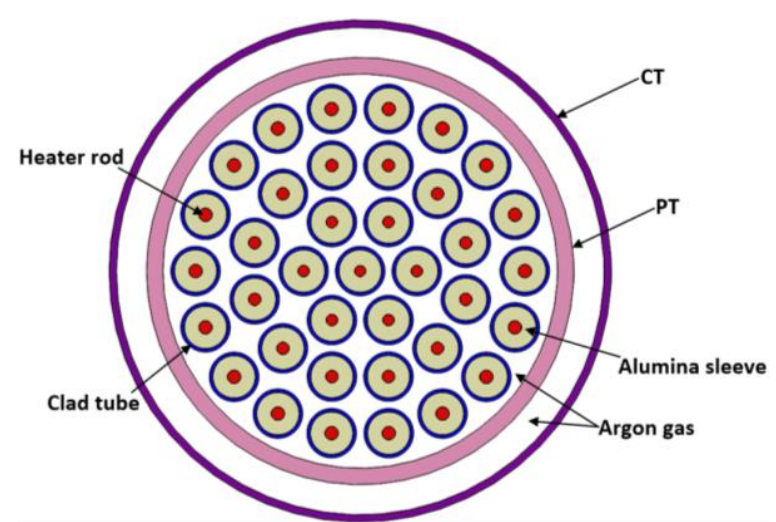

Figure 2: Cross-sectional view of the test-section

The ends of the heater rods were mechanically fastened to the current distributor header made of copper. The total decay heat is distributed in the ratio of 1: 0.843: 0.748: 0.715 among each fuel pin of the fourth, third, second and first ring, respectively. The power ratio is adjusted by using the different diameter of the heater rod. The heater rod of $2.9 \mathrm{~mm}, 3.0 \mathrm{~mm}, 3.25 \mathrm{~mm}$ and $3.5 \mathrm{~mm}$ is used in the fuel pin of first, second, third and fourth ring, respectively. The decay heat of the fuel is simulated by heating the 37-pin fuel bundle simulator using thyristor controlled DC rectifier $(3500 \mathrm{~A} / 140 \mathrm{~V})$. The heating of the fuel bundle is continued until the center fuel pin (pin no-1) attains a steady-state temperature of $700^{\circ} \mathrm{C}$. The temperature data at all positions of the test-section are recorded in the data acquisition system (DAS). 


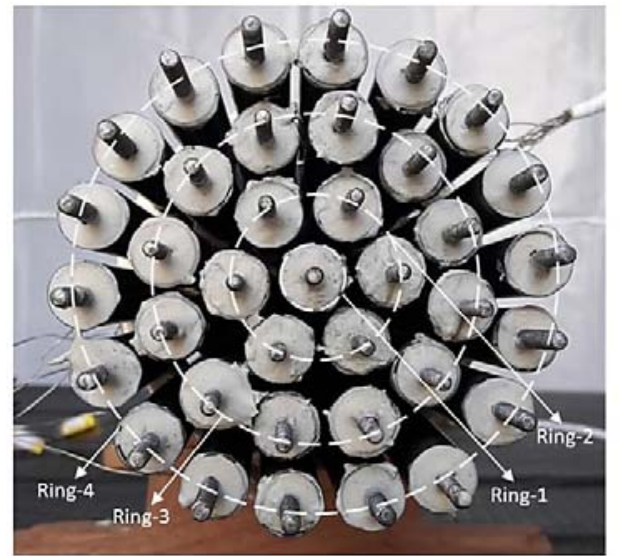

(a)

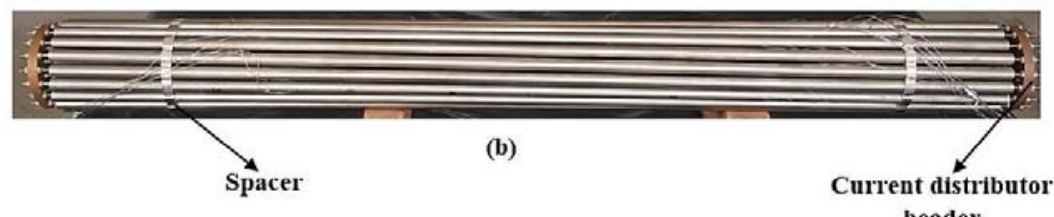

Figure 3: Fabricated fuel bundle simulator: (a) cross-sectional view (b) axial view

The axial and circumferential position of the thermocouple used in the test-section is shown in the Figure 4 and 5.

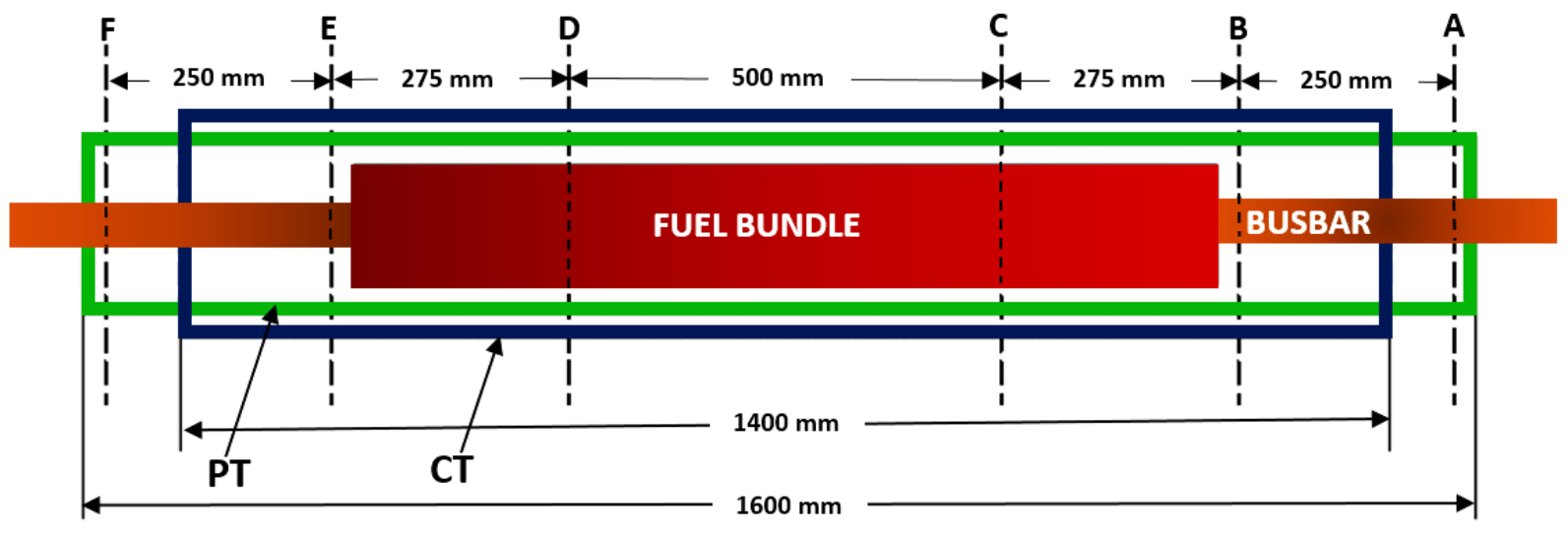

Figure 4: Axial position of thermocouples in the test-section
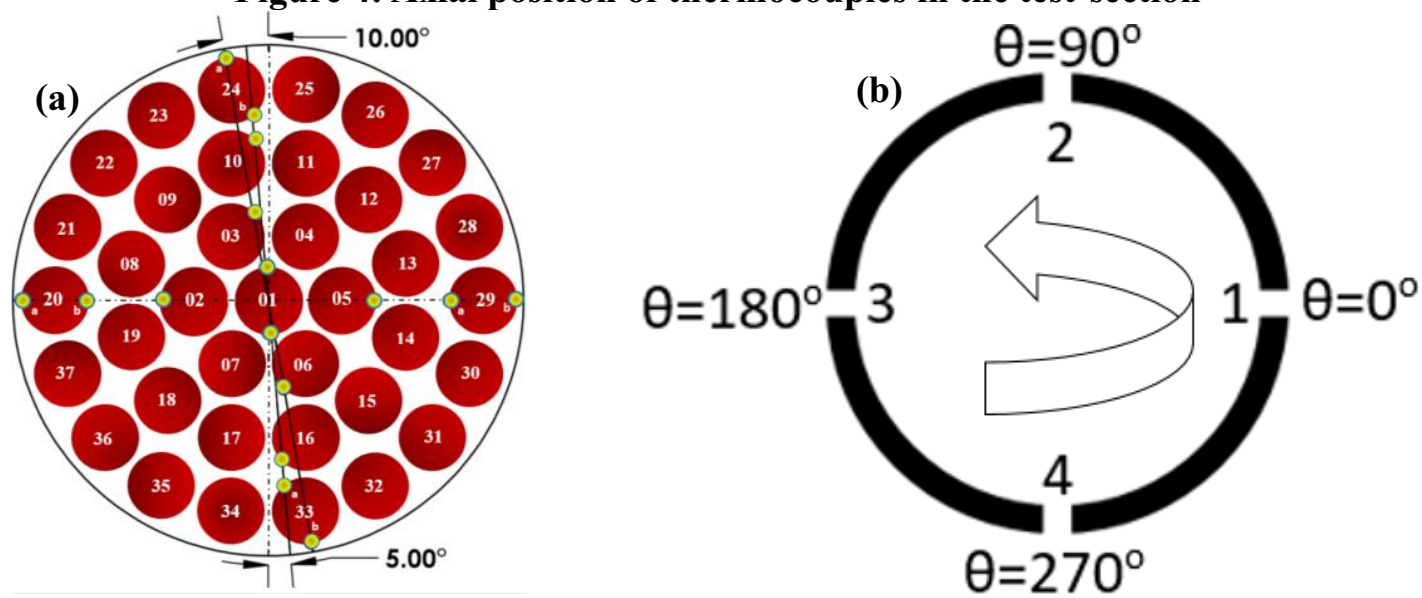

Figure 5: Circumferential position of thermocouples: (a) Fuel bundle (b) PT and CT 


\begin{tabular}{|c|c|c|c|c|c|c|c|}
\hline \multicolumn{2}{|l|}{ Ring-1 } & \multicolumn{2}{|l|}{ Ring-2 } & \multicolumn{2}{|l|}{ Ring-3 } & \multicolumn{2}{|l|}{ Ring-4 } \\
\hline Pin no & Angle $\theta$ & Pin no & Angle $\theta$ & Pin no & Angle $\theta$ & Pin no & Angle $\theta$ \\
\hline $1 \mathrm{a}$ & 90 & 5 & 0 & 10 & 95 & $29 a$ & 0 \\
\hline $1 b$ & 270 & 3 & 100 & 16 & 275 & $29 \mathrm{~b}$ & 0 \\
\hline & & 2 & 180 & & & $24 \mathrm{~b}$ & 95 \\
\hline & & 6 & 280 & & & $24 a$ & 100 \\
\hline & & & & & & $20 \mathrm{a}$ & 180 \\
\hline & & & & & & $20 \mathrm{~b}$ & 180 \\
\hline & & & & & & $33 a$ & 275 \\
\hline & & & & & & $33 b$ & 280 \\
\hline
\end{tabular}

The temperatures of the 37-pin fuel bundle simulator, PT and copper bus bar are measured using K-type thermocouples of $0.5 \mathrm{~mm}$ diameter, while J-type thermocouples of $1.0 \mathrm{~mm}$ diameter are used to measure the temperature of $\mathrm{CT}$ and moderator. The temperature of the fuel bundle simulator is measured at sections $\mathrm{C}$ and $\mathrm{D}$ that were $500 \mathrm{~mm}$ apart. The circumferential position of the thermocouple in the fuel bundle is shown in the Figure 5(a) and Table 2. The temperature of PT and CT is measured at six axial stations (A, $\mathrm{B}, \mathrm{C}, \mathrm{D}, \mathrm{E}$ and F) and (A, B, C and D). For each axial station in PT and CT, four thermocouples are positioned circumferentially at an angular pitch of $90^{\circ}$, as shown in the Figure 5(b). The temperature of the busbar is monitored at sections A, B, E and F to calculate the axial heat loss through conduction. The temperature of the moderator bath is also measured at section $\mathrm{A}, \mathrm{B}, \mathrm{C}$ and $\mathrm{D}$, and for each axial position, three thermocouples are used in such a way that one thermocouple is placed adjacent to the centerline of the $\mathrm{CT}$ and the remaining two are symmetrically opposite to the first one at an axial distance of $150 \mathrm{~mm}$. All thermocouples used are ungrounded, minerally insulated, and covered with Inconel sheath. The temperature measurement uncertainty for K-type thermocouple is $\pm 1.4^{\circ} \mathrm{C}$ at $850{ }^{\circ} \mathrm{C}$, and the same for $\mathrm{J}$ type thermocouple is $\pm 1.5^{\circ} \mathrm{C}$ at $500{ }^{\circ} \mathrm{C}$. The power given to the test-section is measured using a power analyzer.

\section{NUMERICAL METHODOLOGY}

3-D numerical analysis has been performed using ANSYS Fluent 19.0. The geometry of the model used in the analysis is similar to the one used in the experimental study. Each component of the fuel pin, such as Kanthal heater, Alumina sleeve and Zircaloy-4 clad tube is taken in the analysis. The argon gas inside the PT and in the annulus of PT and CT is also considered. The gravity effect of the argon gas is included in the numerical analysis. The computational domain is meshed using hexahedral dominant elements, as shown in the Figure 6. The fine inflation layer is used near the fluid-solid interfaces in order to capture the temperature gradient accurately. The number of elements used in the analysis is 44796300 . The grid independence test has also been performed and it is seen that accurate results are produced with the selected grid size. The semi-implicit pressure linked equation (SIMPLE) algorithm is used to perform the steadystate analysis. The governing equations used in the analysis is shown in the Equation 1-3. The mass, momentum and energy equations are discretized using the second-order upwind scheme.

Continuity equation

Momentum equation

$$
\nabla \cdot(\rho \vec{v})=0
$$

Energy equation

$$
\nabla \cdot(\rho \vec{v} \vec{v})=-\nabla p+\nabla \cdot(\overline{\bar{\tau}})+\rho \vec{g}
$$

$$
\nabla \cdot(\rho e \vec{v})=-\nabla \cdot(k \nabla T)+\nabla \cdot(\overline{\bar{\tau}} \cdot \vec{v})+S_{e}
$$

The radiative heat transfer between the different components of the fuel channel is modeled using the Discrete Ordinates model (Chandrasekhar, 1960) available within Fluent. 


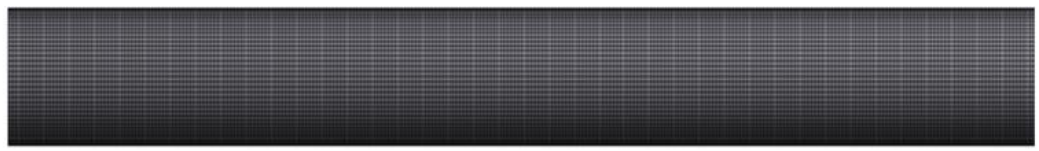

(a)

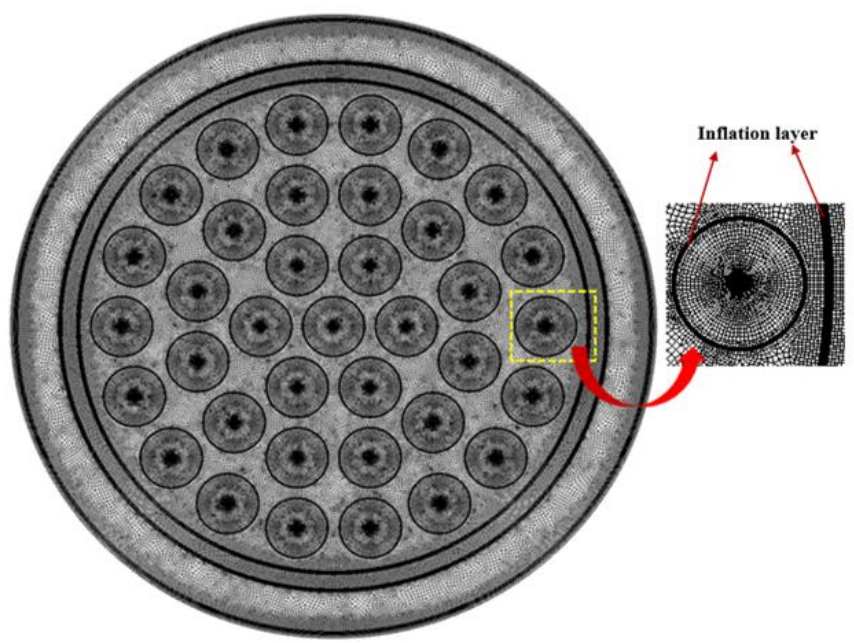

(b)

Figure 6: Meshing: (a) axial (b) circumferential

DO model solves the RTE equation for the discrete number of finite solid angles. The RTE for an absorbing, emitting, and scattering medium at a position $\vec{r}$ in the direction $\vec{s}$ is shown in the Equation 4 .

$$
\frac{d I(\vec{r}, \vec{s})}{d s}+\left(\alpha+\sigma_{s}\right) I(\vec{r}, \vec{s})=a n^{2} \frac{\sigma T^{4}}{\pi}+\frac{\sigma_{s}}{4 \pi} \int_{0}^{4 \pi} I\left(r, \vec{s}^{\prime}\right) \phi\left(s, s^{\prime}\right) d \Omega^{\prime}
$$

The temperature-dependent properties are used for different solids ( $\mathrm{Zr}$ alloy metals, Alumina and Kanthal) and fluid (argon gas) region. The thermal-physical properties and emissivity of Zr-alloy-based materials (PT, CT and fuel pin) have been adopted from the MATPRO. The Dirichlet boundary condition (constant surface temperature) is imposed at the outer surface of the CT. The value of this temperature is taken from the experimental data. The decay heat is modeled by giving a volumetric energy source in each of the heater rods. The total decay heat of $3.3 \mathrm{KW}$ is divided in the ratio of 1: 0.843: 0.748: 0.715 among fuel pins of the fourth, third, second and first ring, respectively. The uniform value of mass flow rate for argon gas $(3 \mathrm{~g} / \mathrm{s})$ was used as an inlet boundary condition, while the pressure outlet was used as the outlet boundary condition.

\section{RESULTS AND DISCUSSIONS}

The temperature of the fuel pins at sections $C$ and $D$ from the experimental data is shown in the Figure 7(a) and $7(\mathrm{~b})$, respectively. It is observed that the temperature of the fuel pins is increasing radially inwards from the fuel pin of the outer ring to the inner ring even though the decay heat is decreasing radially inwards. The average temperature difference between the fuel pin of the first ring to the second, third and fourth ring is $13.52{ }^{\circ} \mathrm{C}, 31.07{ }^{\circ} \mathrm{C}$ and $71.8{ }^{\circ} \mathrm{C}$, respectively. The fuel pin of the center ring attained the highest temperature, which is because surrounding fuel pins of ring-2, ring-3 and ring-4 provide the resistance in the path of its radiative heat transfer. Uniform temperature distribution is seen in the center fuel pin as the maximum temperature difference between its top and bottom node is $2.93{ }^{\circ} \mathrm{C}$ only. The fuel pins of the second ring (2-7) are at a slightly lower temperature than the center fuel pin. Also, each fuel pins of this ring are at a uniform temperature, which is due to the symmetric arrangement. The maximum temperature difference between the symmetrically opposite fuel pin $3 \& 6$ and $2 \& 5$ is $2 .{ }^{\circ} \mathrm{C}$ and $2.3{ }^{\circ} \mathrm{C}$ respectively only. A similar trend in the temperature distribution of the fuel pins of the third ring (pin no 8-19) is reported. 
The average percentage temperature difference of $2.4 \%$ is obtained between diametrically fuel pin 10 and 16.

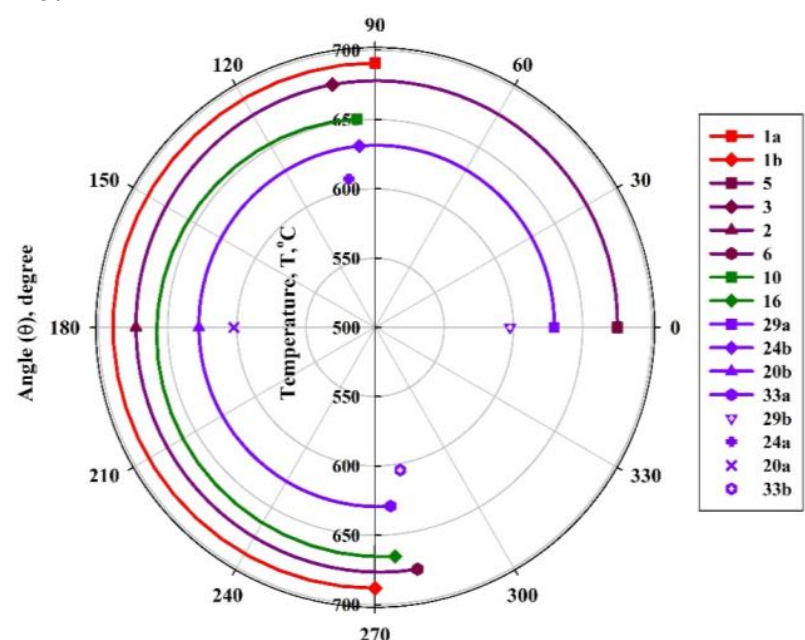

(a)

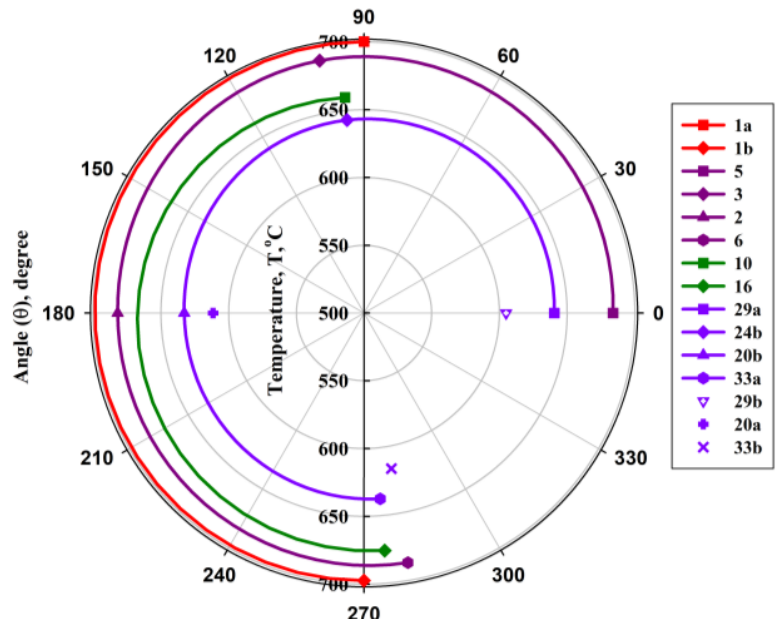

(b)

Figure 7 Circumferential temperature distribution in the fuel bundle: (a) section C (b) section D

The fuel pins of the outer ring attained the lowest temperature as it radiates the decay heat directly to the PT, which is at a relatively lower temperature. In addition, a significant circumferential temperature gradient is obtained in these fuel pins. The nodes adjacent to the PT are at a lower temperature as compared to its diametrically opposite node facing the fuel pin of ring-3 with a maximum percentage temperature of 5.3\% between them. The circumferential temperature distribution of the fuel pins from the numerical analysis at section $\mathrm{C}$ and section D s shown in the Figure 8(a) and 8(b), respectively. The temperature is found to increase linearly from section $\mathrm{C}$ to $\mathrm{D}$ with an average temperature gradient of $24^{\circ} \mathrm{C} / \mathrm{m}$. From the numerical results also a similar decreasing trend of the temperature from the center fuel pin to the outer fuel pin is observed.

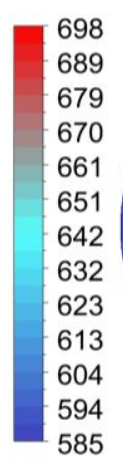

[C]

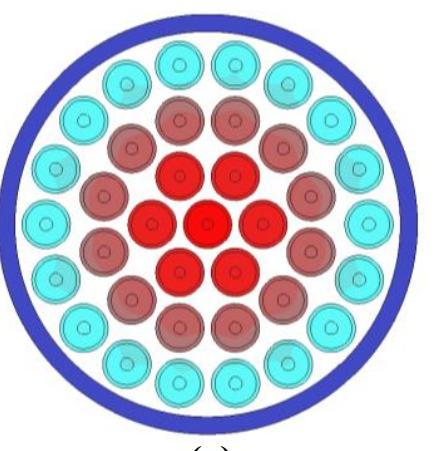

(a)

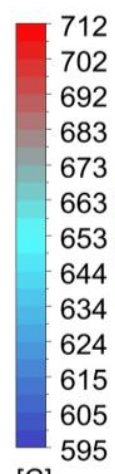

[C

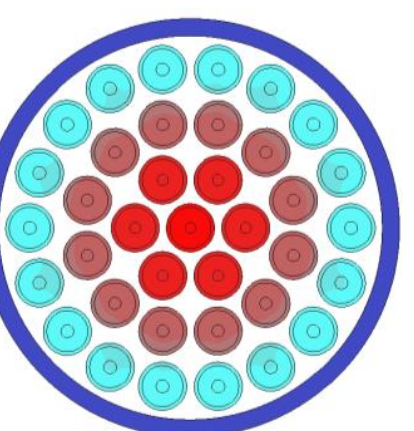

(b)

Figure 8 Temperature contours of the fuel bundle and PT: (a) section C (b) section D

The average percentage temperature difference between the fuel pin of the first ring to the fuel pin of the second, third and fourth ring is $10.2^{\circ} \mathrm{C}, 27.6^{\circ} \mathrm{C}$ and $68.9^{\circ} \mathrm{C}$, respectively. Uniform temperature distribution is also obtained in the fuel pin of each ring, which is also reported from the experiment. The temperature distribution of the argon gas (inside the PT) at section C and D is shown in the Figure 9. The temperature of the argon gas is highly influenced by the temperature of the fuel pins. The circumferential temperature distribution in the PT at each axial station (A, B, C, D and E) from the experiment is shown in the Figure 10. The temperature of the PT is maximum at section $\mathrm{C}$ and $\mathrm{D}$ as compared to the remaining sections as these sections are in the close vicinity of the fuel bundle. In the PT, also uniform circumferential temperature distribution is observed at each axial position. The average temperature difference of $12.3{ }^{\circ} \mathrm{C}$ is seen 
between its top node $\left(\theta=90^{\circ}\right)$ and bottom nodes $\left(\theta=270^{\circ}\right)$. Similar results are obtained through numerical analysis, as shown in the Figure 8 . The maximum percentage temperature difference of $1.2 \%$ is reported between the top and bottom nodes.

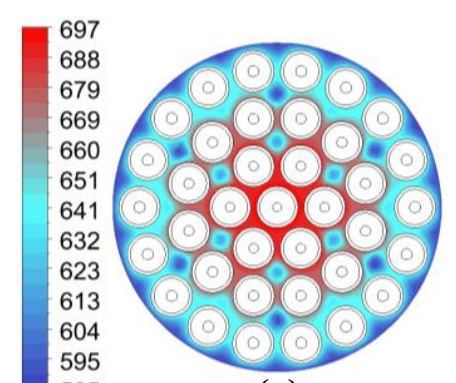

[C] 585

(a)

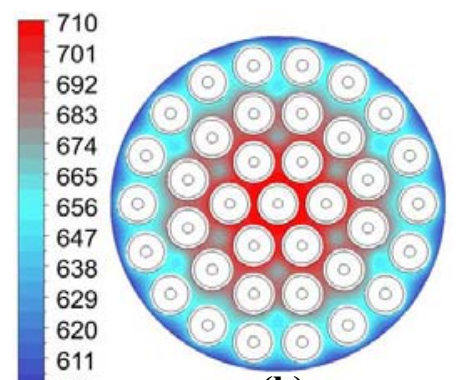

(b)

Figure 9: Temperature distribution of the argon gas inside the channel: (a) section C (b) section D

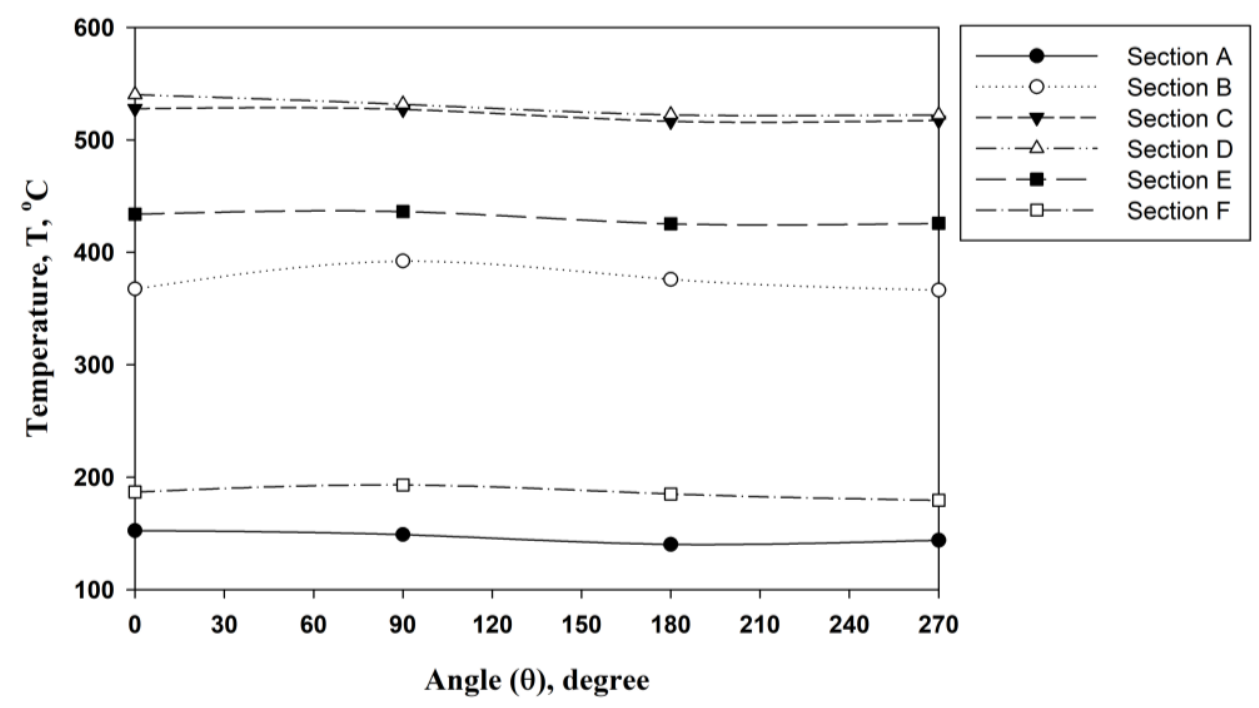

Figure 10: Circumferential temperature distribution in the PT

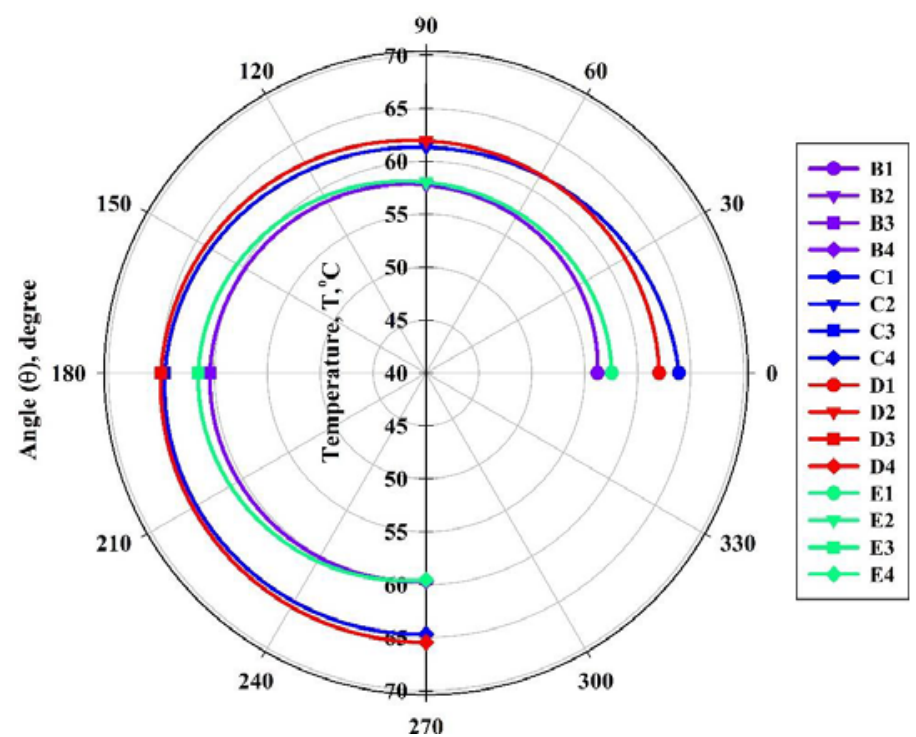

Figure 11: Circumferential temperature distribution in the CT 
The circumferential temperature distribution in the CT from the experimental data is shown in the Figure 10. The temperature of $\mathrm{CT}$ is found to be varied uniformly along its circumference. The average temperature difference between its top and bottom node is $2.5{ }^{\circ} \mathrm{C}$ only. Moreover, there is no significant axial temperature distribution, which confirms that the moderator acts as an active heat sink.

\section{CONCLUSIONS}

The following conclusions are drawn from the experimental and numerical analysis for radiative heat transfer in the coolant channel of an Indian PHWR having 37 fuel pins under deteriorated flow conditions

1. The temperature of the fuel pins is found to increase radially from the outer fuel pin to the inner fuel pin. The average percentage temperature difference between the fuel pin of the first ring to the fourth ring is $11.7 \%$ and $10.4 \%$ from the experimental and numerical study, respectively.

2. No significant circumferential temperature gradient is seen in the fuel pins except for the fuel pins of the outer ring.

3. The temperature of the PT and CT is found to be uniform along the circumference at each of the axial positions.

4. The numerical solution can accurately predict the temperature of the fuel pin within an error of $5 \%$.

\section{REFERENCES}

1. Bhardwaj, S.A., "The future 700 MWe pressurized heavy water reactor." Nuclear Engineering and Design 236, 861-871 (2006).

2. Bajaj, S.S., Gore, A.R., "The Indian PHWR." Nuclear Engineering and Design 236, 701-722 (2006).

3. Gupta, S.K., Dutta, B.K., Venkat Raj, V., Kokodkar, A., "A Study of the Indian PHWR Reactor Channel Under Prolonged Deteriorated Flow Conditions." International Atomic Energy Agency, Vienna (Austria), pp. 331-359 475 (1997).

4. Mukhopadhyay, D., Majumdar, P., Behera, G., Gupta, S.K., Raj, V.V., "Thermal analysis of severe channel damage caused by a stagnation channel break in PHWR." J Pressure Vessel Technol., 124, 161-167 (2002).

5. Ajay, Ketan, Kumar, Ravi, Mukhopadhyay, Deb., Gupta, Akhilesh, Gokhale, Onkar, Das, Arup K., "Experimental investigation of radiation heat transfer in coolant channel under impaired cooling scenario for Indian PHWR." Nucl. Eng. Des., 347, 45-52 (2019).

6. D. Bowslaugh, " CHAN-IIA MOD 2.0: Prediction of CANDU Fuel Channel Behaviour Under Prolonged Low Flows - Program Description," TTR-490, Atomic Energy of Canada Limited. (1993).

7. B. N. Hanna,. "CATHENA :A thermalhydraulic Code for CANDU analysis." Nucl. Eng. Des., 180[2], 113-131 (1998).

8. Kim, Hyoung Tae, Rhee, Bo Wook, Park, Joo Hwan, " Benchmark calculations of a radiation heat tansfer for a CANDU fuel channel analysis using the CFD Code." Journal of Nuclear Science and Technology, 43:11, 1422-1430 (2012).

9. Nandan, Gopal, Sahoo, P.K., Kumar, Ravi, Chatterjee, B., Mukhopadhyay, D., Lele, H.G., "Experimental investigation of sagging of a completely voided pressure tube of Indian PHWR under heatup condition.” Nucl. Eng. Des., 240, 3504-3512 (2010).

10. Yadav, Ashwini K., Majumdar, P., Kumar, Ravi, Chatterjee, B., Gupta, Akhilesh, "Experimental simulation of asymmetric heat up of coolant channel under small break LOCA condition for PHWR." Nucl. Eng. Des., 255, 138-145 (2013).

11. Niteanandan, T., July-04, "Test result for the IAEA International Collaborative Standard Problem on Heavy Water Reactor Moderator Subcooling Requirements.” AECL (2014).

12. Ajay, Ketan, Kumar, Ravi, Mukhopadhyay, Deb., Gokhle, Onkar, Gupta, Akhilesh, \& Das, Arup K., "Influence of PT-CT contact on PHWR fuel channel thermal behaviour under accident condition-An experimental study." Nuclear Engineering and Design, 361, 110543 (2020). 
13. Ajay, Ketan, Kumar, Ravi, \& Gupta, Akhilesh, "Thermal analysis of single channel for pressurized heavy water reactor during LOCA-A numerical approach." In Proceedings of the 25th National and 3rd International ISHMT-ASTFE Heat and Mass Transfer Conference (IHMTC-2019). Begel House Inc., (2019). 